\title{
Study on the Relationship between Aspects, Orientation, Type, and Unit Position toward to Indoor Air Quality in Flat
}

\author{
Arief Sabaruddin $^{1^{*}}$, Tri Harso Karyono ${ }^{2}$, Rumiati R. Tobing ${ }^{3}$ \\ ${ }^{1}$ Research Institute for Human Settlements, Ministry of Public Works, Bandung, Indonesia \\ ${ }^{2}$ School of Architecture, Tarumanagara University, Jakarta, Indonesia \\ ${ }^{3}$ School of Architecture, Parahyangan Catholic University, Bandung, Indonesia \\ Email: *ars@puskim.pu.go.id \\ Received January 16, 2013; revised March 29, 2013; accepted April 6, 2013
}

Copyright (C) 2013 Arief Sabaruddin et al. This is an open access article distributed under the Creative Commons Attribution License, which permits unrestricted use, distribution, and reproduction in any medium, provided the original work is properly cited.

\begin{abstract}
Thermal factor is one of the main factors of the green building concept. The purpose of this research is to test building performance through design aspect that influences thermal comfort, the design aspects include: orientation, building type, and position of the flat. Method used in this research is covariance analysis, testing the influence of factor variable toward respond variable (indoor temperature) with taking outdoor temperature as concomitant variable. The cases tested on this research are Cigugur Tengah, Industri Dalam, and Sarijadi flats. Result of covariance analysis shows that the building orientation factor variable is most influentially variable toward thermal comfort, compared with building type factor variable; even the unit position factor variable has no significant influence toward thermal comfort.
\end{abstract}

Keywords: Orientation; Building Type; Unit Position; Thermal; Flat House; Selective Design

\section{Introduction}

\subsection{Background}

Architecture is responsible to energy consumption, according to data of American Institute of Architects (AIA), buildings in United State of America consume $48 \%$ of energy, followed by transportation $27 \%$ and industry $25 \%$ [1]. While electrical power consumption for buildings attains $76 \%$. In the building comfort aspect, in Indonesia $60 \%$ of average energy is needed to increase the indoor air quality.

Energy consumption in Indonesia is $850.83 \mathrm{~kg}$ equivalent to oil per capita [World Bank: 2009], energy per capita consumption potential increases as national population growth increase of $5.2 \%$ of economic growth, so it can be predicted that the energy consumption will also increase. Energy source that is used is mainly from fossil fuel i.e. coal, the popular fuel in power plant. Effect of coal combustion is about 970 grs per $\mathrm{kWh} \mathrm{CO}_{2}$ emissions, twice more than oil fuel, which produces of 540 grs $\mathrm{CO}_{2}$ per kWh.

Requiring thermal comfort on building has the most

${ }^{*}$ Corresponding author. effect toward energy consumption and $\mathrm{CO}_{2}$ emissions. So, this research focuses on design variables which have been influenced by energy consumption. Design variables tested on this research is according to general characteristic of selective design adapted by Hawkes [2]. In this case, Hawkes extends five main characteristics, including internal environment, which the measurement concerned to micro climate, notably through temperature control that is work by the building itself.

Second characteristic from Hawkes is built form that is form of building concerned to specific local climate; for example, with sufficient of the sun light, the form of building should make the best use of the sun light for day lightening. Buildings located on the high rainfall places should have long covered passageway, as form behavior of the rainfall. According to Hawkes, form is influenced by local climate characteristic. In flat building design of low $\mathrm{CO}_{2}$ emissions context, are the building form has good performance toward $\mathrm{CO}_{2}$ emission? The study of flatbuilding form in Indonesia is object on this research.

There are three typologies of flat form in Indonesia; firstly, is tower flat, for example Cigugur Tengah Flat in Cimahi, suburb of Bandung City; secondly, is longitudinal type flat, which is classified into two typologies, 
the single loaded and the double loaded. Double loaded type flat such as Industri Dalam Flat in Bandung City and single loaded flat in Sarijadi Flat.

The third selective design characteristic is orientation; building orientation is concerned with building location which is concerned with sun-path diagram. Exuberate sun light in Indonesia generally gives positive effect today lightening system in building. But in contrast with thermal, much sun light will decrease thermal comfort, that condition has a high temperature tendency, according to BMKG average temperature in Bandung is of $22.9^{\circ} \mathrm{C}$. According to result of Karyono's research [3] on research to architecture student in ITB, range of thermal comfort of the respondents isof $23^{\circ} \mathrm{C} \mathrm{T}_{\mathrm{g}}$ to $-26.5^{\circ} \mathrm{C} \mathrm{T}_{\mathrm{g}}$.

The fourth characteristic is fenestration, which is concern of local climate where the windows position must balance and related to the thermal condition and environmental light. And the fifth characteristic is energy sources, paying attention to energy source used with prioritizing benefits of environmental light source optimally through passive design approach. Those five general characteristics of selective design proposed by Hawkes don't have the most influencing characteristic information. So, this research is for exploring which characteristic influence the flat design on the flat for low income citizens in Bandung.

\subsection{Research Goal}

This study focused on testing the theory of selective design of Olgyay and Banham, and to determine its relevance to the tropical climate in Indonesia.

The aim of this research is to measure building performance toward adapting ability of the environment (micro climate). Building performance aspects tested including of the orientation, the building types and the flat position toward the ability to produce of good building comfort level.

Moreover, this research is also purpose to find out which design factors that most influencing toward thermal comfort, through covariance analysis, that including to the outdoor temperature variable as direct variable that influence to indoor temperature.

\subsection{Problem Formulation}

Buildings have function to protect the occupants from environmental annoyances; one of the annoyances is an outdoor thermal annoyance. Thermal comfort is one of the building aspects that potentially produce the highest number of $\mathrm{CO}_{2}$ emission. Through building design, hopefully thermal comfort can be reached. Some design variables that have influence toward comfort according to Hawkes [2] must be tested, which one has most influence? This research tested only three of five variables according to Hawkes, i.e. 1) internal environment/micro climate, 2) building form/typology, and 3) building orientation. Building forms on this research are described into several types according to the circulation pattern; and vertical-and-horizontal flat unit composition.

\section{Theory}

Building thermal comfort performance is determined by indoor temperature quality. According to the indicators published by Green Building of Indonesia, one of the indicators is indoor air quality. Building must be able to response outdoor temperature to produce indoor comfort air quality. According to Hawkes [2], general characteristic of selective design toward environment which is firstly sparked by Olgyay and Banham [2], are consists of five consideration, i.e. 1) Internal environment, 2) Built form, 3) Orientation, 4) Fenetration, and 5) Energy Source. Buildings response those design variables, the response hopefully can produce indoor air quality that gives comfort. So, indoor temperature is response variable toward design factor variables. On this research, factor variables tested are building orientation factor, built form and unit position.

Building orientation factor variable consists of four levels, i.e. north 1), west 2), south 3), and east 4) Building type factor variable consists of four type, 1) tower type with Cigugur Tengah Flat as its sample, 2) double loaded block type with Industri Dalam Flat as its sample, and 3) single loaded block type with Sarijadi Flat as its sample. While unit position factor variable consists of nine levels, i.e. 1) left-below position, 2) left-centered, 3) left-top, 4) centered-below, 5) center-center, 6) center-top, 7) right-below, 8) right-center, and 9) right-top.

Indoor temperature response variable has dynamic character because of the outdoor temperature variable, in this case was defined as micro-climate equivalent to Hawkes [2] defined as internal environment, which also influenced by macro-climate on city scale or regional. So, indoor temperature variable can not be controlled during the measuring process, then on the same time outdoor temperature is also measured and described as concomitant variable [4]. Mechanism of influence of those three variables is descripted at Figure 1.

Outdoor temperature as concomitant variable is dynamic and can not be controlled, but can be measured, outdoor temperature variable directly influence the response variable (indoor temperature), but outdoor temperature variable has no any influence toward factor variable, on the contrary factor variable will influence indoor temperature variable. Number of indoor temperature depends on number of outdoor temperature which gets influence from factor variable. Factor variable functions as filter toward external environment. Factor vari- 


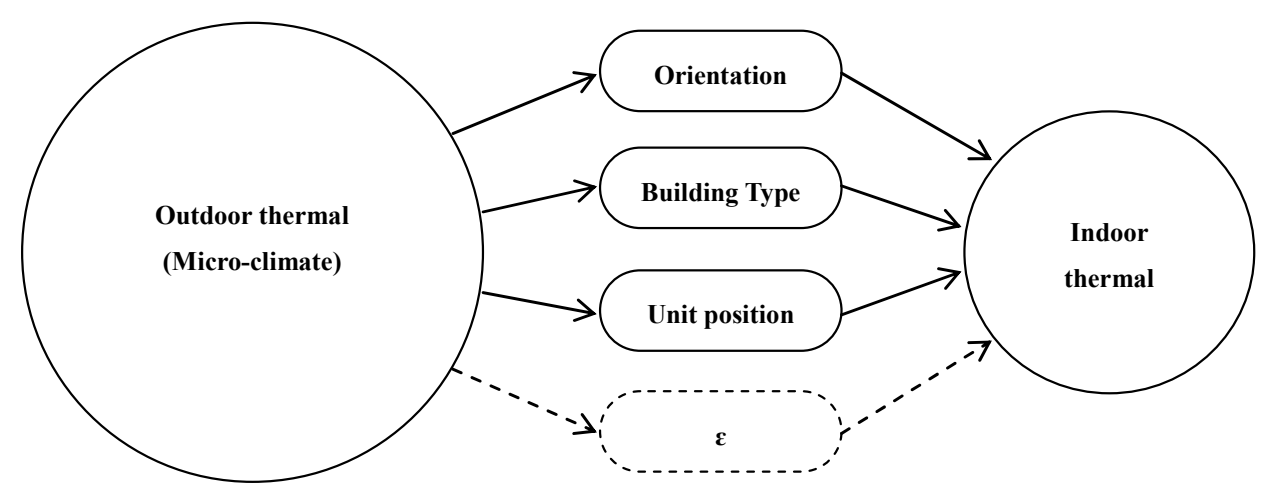

Figure 1. Structural equation model of the influence of design on thermal comfort.

able is kind of treatment, where each treatment will influence the number of indoor temperature. So, it can be formulated on this research as shown on Equation (1):

$$
Y=X+\sum_{1}^{n} f
$$

\section{Note:}

$Y=$ Indoor thermal $\left({ }^{\circ} \mathrm{C}\right.$-indoor air quality $)$

$X=$ Outdoorthermal $\left({ }^{\circ} \mathrm{C}\right)$ - micro climate $)$

$f=$ Factor variables

On influencing indoor temperature, design factor variables can have positive and negative quality. If factor variable have positive quality, then outdoor temperature rising will be followed by indoor temperature rising, and outdoor temperature descent will be followed by indoor temperature descent. On contrary if factor variable has negative quality. Outdoor temperature raise will be followed by indoor temperature descent, and outdoor temperature descent will be followed by indoor temperature raise. So, if design factor variable equals to zero, then whole indoor temperature will equals to outdoor temperature. This condition happened on outdoor without any design element.

Problem on this research is a building from the five selective design variables according to Hawkes [2], is not known yet, which design factor variable is most influence? How much is each variable influence indoor air quality? Are there more variables that are not found yet into the five selective design variables? This research focuses to flat building for low income citizen.

\section{Method}

Analysis method used is covariance analysis that is statistical analysis method using three variables; there are variable response, variable factor, and variabel concomitant, in this case, the dependent variable (response) is indoor temperature; the concomitant variable is outdoor temperature; and factor variables are aspects of building design. Between concomitant variable, there is no influence from factor variable, it means there is no relationship between outdoor temperature and design variable.
Response variable is influenced by concomitant variable; there is regression between both variables. Concomitant variable functions as control variable, to see the influence of factor variable toward response variable without any influence from concomitant variable.

Indoor and outdoor temperature data are obtained from direct measure using globe thermometer (T-globe). Temperature measurement is measured in each unit of samples and outdoor temperature every hour, which the measurement range is from 7:00 am to $18: 00 \mathrm{pm}$, so that there are twelve times measurements on one day. Total samples taken per case are nine; those nine samples represent each character which is different according to unit position.

The research is located in Bandung, with samples chosen are Cigugur Tengah Flat, Industri Dalam Flat, and Sarijadi Flat, each of them represent flat design typology tower type, double loaded block type, and single loaded block type. Factor variable data is category type, which is ordered according to orientation variable, building type and unit position. While indoor and outdoor temperature is ratio data.

Covariance analysis functions to test influences between the variables. The result is influence coefficient of each factor variable, and influence of interaction between factor variables. Factor variable consists of orientation, temperature, building type, and unit position, while interaction of factor variable include; interaction between orientation*unit-position, interaction building type*unit position, intercation orientation*building-type, and interaction orientation*building-type*unit position. Number of influence is read through partial ETA square number, that equivalent to Adjusted $R^{2}$ on general regression.

\section{Discussion and Analysis}

Indoor temperature variable data is normal distributed toward outdoor temperature variable, and the relationships of both variables are linear. Multy-colinearity test was done for finding out if there is correlation between factor variable (orientation, building type, and unit posi- 
tion). Its results shows that VIF (variance inflation factor) value equals one, it means there is no correlation between orientation, type, and unit position variables.

Minimum outdoor temperature is $23.90^{\circ} \mathrm{C}$, maximum temperature is $31.30^{\circ} \mathrm{C}$, with deviation standard is 1.57 to $7.4^{\circ} \mathrm{C}$ range. There are 1926 measurement results as total collected data $(\mathrm{N})$, where each flat are measured twelve times, on each building there are nine samples taken from each flat. Average temperature data based on day time scale, between 7:00 am-18.00 pm; are showed in Table 1.

Correlation between factor variable toward indoor temperature variable isanalyzed by inputting outdoor temperature control variable. Correlation test result shows that orientation and type factor variable is correlated with indoor temperature variable, the value of orientation variable correlation coefficient is 0.250 and type variable coefficient is 0.100 , while the correlation number of unit position factor variable is 0.030 ; with 0.283 sig. number, more than 0.050 .

The purpose of this research is to find out if there is influence of flat design factor variable toward indoor temperature with inputting concomitant variable [4]. Indoor temperature variable is always changing as outdoor temperature variable changes, so there is regression between outdoor temperature and indoor temperature variable, and also influenced by building design variables (orientation, type, and unit position), that can be described on Equation (2) below:

$$
\begin{aligned}
& Y_{i j}=\mu+\beta\left(X_{i j}-\bar{X}\right) \\
& +\left(\tau_{O}+\tau_{T}+\tau_{P}+\tau_{O T}+\tau_{O P}+\tau_{T P}+\tau_{O T P}\right)+\varepsilon_{i j}
\end{aligned}
$$

Note:

$\beta$ : Indoor to outdoor regression coefficient

$\bar{X}$ : Average outdoor temperature

$i$ : Number of factor variable

$j$ : Number of observation

$\tau$ : Factor variables (orientation, building type, unit position, orientition*building type, orientation*unit position, building type*unit position, and orientation *building type*unit position)

$\mu:$ Constanta/efect

$\varepsilon:$ Other effects

Table 1. Average indoor and outdoor temperature.

\begin{tabular}{ccccc}
\hline \multirow{2}{*}{ Temperature } & \multicolumn{4}{c}{ Building type (Sample) } \\
\cline { 2 - 5 } & $\begin{array}{c}\text { Cigugur } \\
\text { tengah }\end{array}$ & $\begin{array}{c}\text { Industri } \\
\text { dalam }\end{array}$ & Sarijadi & Total \\
\cline { 2 - 5 } & Mean & Mean & Mean & Mean \\
\hline Indoor & 26.07 & 27.41 & 27.28 & 26.92 \\
Outdoor & 26.20 & 27.61 & 27.79 & 27.20 \\
\hline
\end{tabular}

The formula above shows merger of regression analysis and analysis of variance. As stated on rule of using analysis of covariant method, there must be strong linear regression relationship between outdoor temperature variable and indoor temperature variable. Result of response variable and concomitant variable regression test shows 0.687 of regression coefficient $(\beta)$, that means there is strong influence relationship and $31.3 \%$ still influenced by another variables. The 0.687 or $68.7 \%$ regression coefficient is used for purring concomitant variable (outdoor temperature) influence toward response variable (indoor temperature).

Second rule said that there must not be any relation between concomitant variable and factor variable. Result of regression test of outdoor temperature variable toward factor variable (orientation, type, and unit position) shows that the $R$ number is less than zero. And so do factor variables, there is no correlation, that explained by less than 0.05 sig. value.

Covariance analysis result (Table 2) shows Adjusted $R^{2}$ value is 0.551 or corrected model has Partial Eta Squared $\left(\mu_{p}^{2}\right)$ of 0.558 , so this model is suitable for looking the relationship between orientation, building type, unit position, and interaction orientation*building type, orientation*unit position, building type*unit position, and orientation*building type*unit position. Existentof factor variable's influence toward response variable, can be looked from sig. number, if sig. number less than 0.05 then factor variable is influencing, if probability value (sig.) number more than 0.05 then factor variable is not influencing toward response variable.

Based on covariance analysis result on Table 2, shown that factor variables, that influences temperature are orientation, building type, unit position, and interaction between building type and orientation variable. So, mathematical model resulted is Equation (3):

$$
Y_{i j}=\mu+\beta\left(X_{i j}-\bar{X}\right)+\left(\tau_{O}+\tau_{T}+\tau_{P}+\tau_{O T}\right)+\varepsilon_{i j}
$$

Note:

$\beta$ : Indoor to outdoor regression coefficient

$\bar{X}:$ Average outdoor temperature

$i$ : Number of factor variable

$j$ : Number of observation

$\tau$ : Factor variables (orientation, building type, unit position, orientition*building type)

$\mu:$ Constanta /effect

$\varepsilon:$ Other effects

On covariance analysis model, shown that factor variable that mostly influences to indoor temperature quality is orientation factor variable with $\mu_{p}^{2}$ value is 0.127 or the value of influence of orientation toward unit comfort is $12.7 \%$ and very influencing, it's shown from sig. number 0.000 , much less than 0.05 . 
Table 2. Test of effect the factor variables to respond variable.

\begin{tabular}{|c|c|c|c|c|c|c|}
\hline Source & $\begin{array}{l}\text { Type III Sum of } \\
\text { Squares }\end{array}$ & $\mathrm{df}$ & $\begin{array}{l}\text { Mean } \\
\text { Square }\end{array}$ & $\mathrm{F}$ & Sig. & $\begin{array}{l}\text { Partial Eta } \\
\text { Squared }\end{array}$ \\
\hline Corrected Model & $1517,221^{\mathrm{a}}$ & 108 & 14,048 & 15,716 & 0.000 & 0.588 \\
\hline Intercept & 420,702 & 1 & 420,702 & 470,647 & 0.000 & 0.284 \\
\hline Out door thermal (micro climate) & 811,364 & 1 & 811,364 & 907,688 & 0.000 & 0.433 \\
\hline Orientation $(\mathrm{O})$ & 154,596 & 3 & 51,532 & 57,650 & 0.000 & 0.127 \\
\hline Bulding type (T) & 51,553 & 2 & 25,776 & 28,836 & 0.000 & 0.046 \\
\hline Unit position $(\mathrm{P})$ & 19,019 & 8 & 2377 & 2660 & 0.007 & 0.018 \\
\hline Orientation*Building type $(\mathrm{O} * \mathrm{~T})$ & 19,924 & 6 & 3321 & 3715 & 0.001 & 0.018 \\
\hline Orientation*Unit position $(\mathrm{O} * \mathrm{P})$ & 11,069 & 24 & 0.461 & 0.516 & & 0.010 \\
\hline Building type*Unit position $(\mathrm{T} * \mathrm{P})$ & 20,557 & 16 & 1285 & 1437 & & 0.019 \\
\hline Orientition*Bld type*Unit position $\left(\mathrm{O}^{*} \mathrm{~T} * \mathrm{P}\right)$ & 19,859 & 48 & 0.414 & 0.463 & & 0.018 \\
\hline Error $(\varepsilon)$ & 1061,035 & 1187 & 0.894 & & & \\
\hline Total & 941943,050 & 1296 & & & & \\
\hline Corrected Total & 2578,257 & 1295 & & & & \\
\hline
\end{tabular}

Respon Variable (dependent variable) : Indoor Thermal $\left({ }^{\circ} \mathrm{C}\right)$ as indoor air quality. ${ }^{a} R^{2}=0.588\left(\right.$ Adjusted $\left.R^{2}=0.551\right)$.

Influence of building type factor variable toward indoor temperature is significant enough with $\mu_{\mathrm{p}}{ }^{2}$ value is 0.046 . While unit position factor variable is according to 0.007 significance number, shows that there is influences of unit position variable toward indoor temperature, based on $\mu_{\mathrm{p}}^{2}=0.018$ value, the influence is minor, because less than $2 \%$. According to that result, it can be concluded that strong influences are happened to orientation and building type factor.

To find how much factor variables influence indoor temperature with outdoor temperature as control variable, then Beta value is observed through regression test, that value shows influences rank of each variables. Result of beta value regression test is shown on Table 3. Orientation is more important than building type. While unit position factor variable doesn't influence indoor temperature, it can be explained by sig. value 0.252 that more than 0.050 .

To test further about orientation variable, then strength of orientation variables of the three building samples are tested. The result is ratio of orientation's influence on each flat, as shown at Table 4. Building orientation role mostly influence toward Cigugur Tengah Flat and Sarijadi Flat, while on Industri Dalam Flat orientation seems has no major influence. But that condition can not be concluded like that because of samples measurement position is on surrounded by corridor and another rooms condition.

Model on Table 3. Influence of orientation with input- ting type variable of 0.182 , if compared with Table 4 . Influence of orientation on each flat, seems that orientation variable has strong influence on Cigugur Tengah and Sarijadi Flat, every one of them has beta value of 0.236 and 0.248 , it means orientation variable is stronger on Sarijadi Flat than on Cigugur Tengah Flat. On contrary with Industri Dalam Flat, where is beta number is fewer than beta number on Table 3. It means orientation variable on Sarijadi Flathas no strong influence.

Unit position variable on Table $\mathbf{3}$ shows that there is no influence toward indoor temperature variable, it was stated from multi regression analysis test with 0.022 beta value and 0.252 sig. number, much better than 0.05 . Based on Table 4, the unit position in Sarijadi flat influences indoor temperature. Unit position variable has influences on flat with slender and longitudinal form. Influence of unit position on Flat will be showed by quality result value using $\mathrm{z}$-score, showing a clear pattern, more top more heat (temperature) of flat.

Influence of building type on various orientation shows that west and east orientation have major influences toward indoor temperature variable. Building type variable is very influencing when building is east faced, it's showed with beta value of building type toward indoor temperature on east orientation is of 0.202 (largest value), next on west orientation with of 0.128 beta value. Influence of building type toward indoor temperature on north and south orientation is very minor, even on south orientation, type variable does no influence to the re- 
sponse variable, with beta value less than 0.05 . refer to Table 5.

Based on Table 5, influence of building type toward thermal comfort is very strong on building direction with west and east orientation, where east orientation is the most influencing with beta coefficient of 0.202 , while west orientation has beta value of 0.128 . Ideal orientation for flats in Bandung is south orientation, its beta coefficient equals to 0.040 , shows that any type of building in this case has not any influence toward indoor temperature when flats are south faced.

\section{Conclusions}

Result of this research shows that from the three tested design factor variables, it can be concluded that two factor variables have significant influence toward thermal comfort in flats. Variable that influences significantly is orientation factor variable with correlation coefficient or beta value is of 0.081 . While, the unit position variable does not have a significant effect on indoor thermal, it is shown from beta value or correlation coefficient of 0.022 , less than 0.05 . Influence of outdoor temperature toward indoor temperature on whole building is major with correlation coefficient reaches 0.653 .

Factor variable's influence pattern toward thermal comfort in covariance analysis is : indoor air quality in flat units is influenced by orientation factor variable, type factor variable, unit position factor variable, and also influenced by interaction between orientation*type factor variable. This pattern is shown by formula (3) at preface chapter. Structural formula of factor variable's influence represent of $58.8 \%$ and $41.2 \%$ still contained on another variables that is not measured on this research.

The influence of outdoor temperature (micro climate) toward thermal comfort in the flats is very high and could reach $47 \%$. Further study about micro climate handling in flats will need to be conducted, and a method to

Table 3. Effect of design (building form) toward thermal comfort.

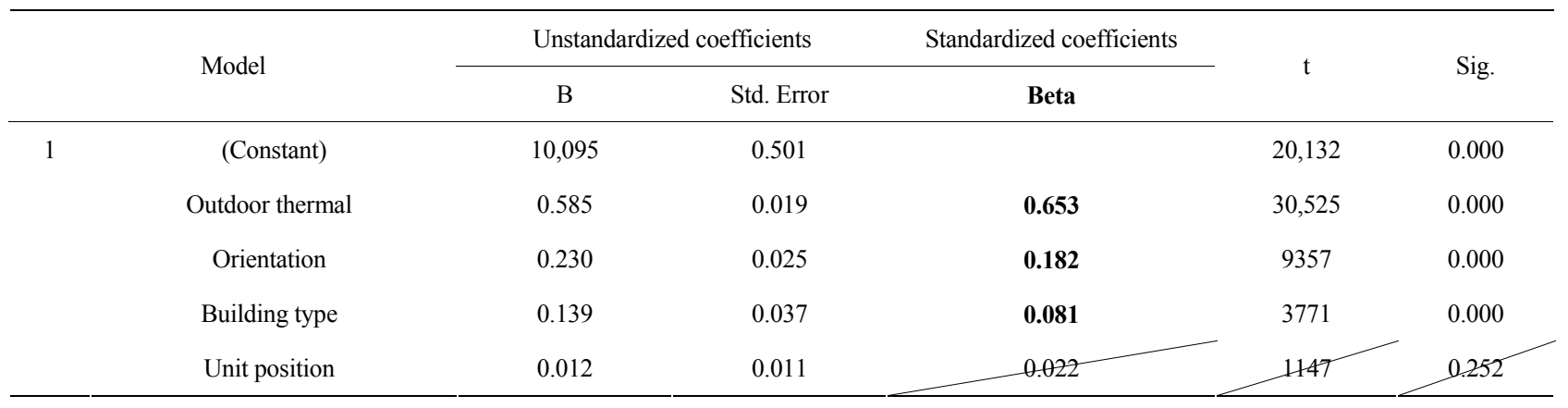

Table 4. Beta coefficient according to difference of Building form.

\begin{tabular}{|c|c|c|c|c|c|}
\hline \multirow{2}{*}{ Building type } & \multicolumn{3}{|c|}{ Beta coefficient $(\beta)$} & \multirow{2}{*}{$R$} & \multirow{2}{*}{$R^{2}$} \\
\hline & Outdoor thermal & Orientition & Unit Position & & \\
\hline Industri Dalam & 0.417 & 0.095 & 0.001 & 0.425 & 0.175 \\
\hline Sarijadi & 0.772 & 0.248 & 0.061 & 0.837 & 0.699 \\
\hline Total & 0.686 & 0.182 & 0.022 & 0.711 & 0.504 \\
\hline
\end{tabular}

Table 5. Beta coefficient according to difference of orientation.

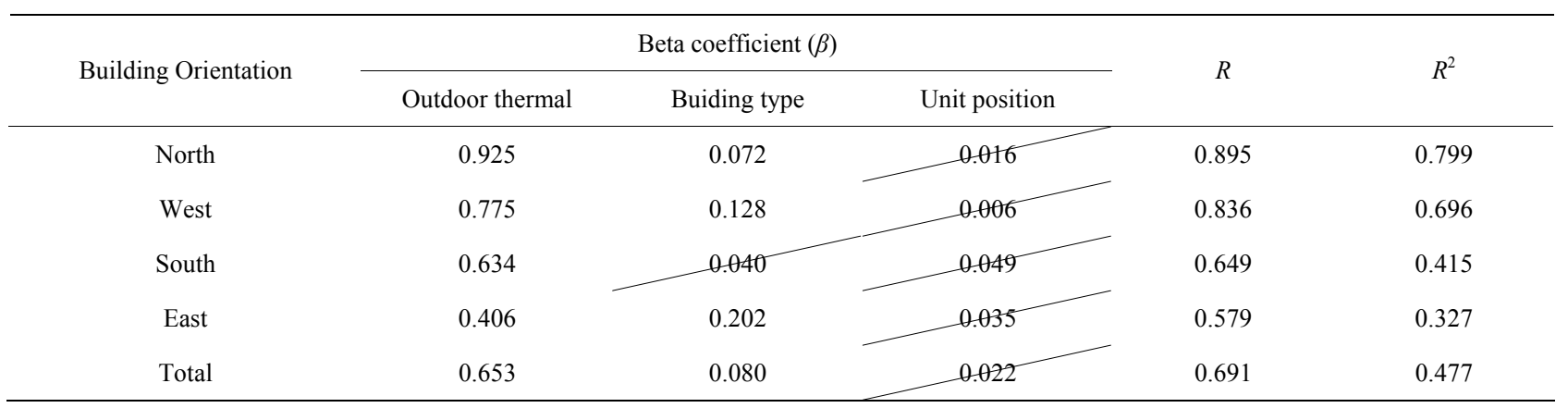


increase micro climate quality in flats will need to be found. The level of thermal comfort in flats is really influenced by micro climate; while micro climate is highly influenced by macro climate. From micro climate aspect, it could be conducted further research about the influence of landscape design, such as width of harden area, quantity and type of plants, etc.

\section{REFERENCES}

[1] O. Attmann, "Green Architecture, Advanced Technologies and Material,” Mc Graw Hill Companies, 2010.
[2] D. Hawkes, J. McDonald and K. Steemers, "The Selective Environment, Approach to Environmentally Responsive Architecture," Spon Press, London, New York, 2002, pp. 1-14.

[3] T. H. Karyono, "Building Termal Comfort Study: Assessing the Applicability of an Adaptive Model in Indonesia," Architecture Science Review, Vol. 51, No. 1, 2008, pp. 59-64.

[4] Sudjana, "Disain dan Analisis Eksperimen," Penerbit Tarsito, Bandung, 1991, pp. 263-273.

[5] GBCI, "Green Building Council of Indonesia," 2012. http://www.gbcindonesia.org/ 